was reported. Finally, indirect costs and benefits of fire-related injuries were studied.

Conclusions Conducting an incidence-based cost of illness study requires detailed person-level data. Due to multiple sources and raw data being administrative on nature makes the research burdensome. Annually on average direct and indirect costs exceed EUR 40 million (population 5.4 million). Majority of the costs are indirect.

\section{COOL RUNNINGS: A NOVEL APPROACH TO PREVENTING HOT BEVERAGE SCALDS IN YOUNG CHILDREN}

'Jacqueline Burgess, ${ }^{1}$ Roy Kimble, ${ }^{2}$ Kerrianne Watt, ${ }^{3}$ Cate Cameron. ${ }^{1}$ University of Queensland, Australia; ${ }^{2}$ James Cook University, Australia; ${ }^{3}$ Griffith University, Australia

\subsection{6/injuryprev-2016-042156.412}

Background Burn injuries are common in young children, and one of the leading causes is hot beverage scalds. Innovative new technologies such as Smartphone applications (apps) present a novel way for delivering individual-level behaviour change messages. When combined with gamification (using game techniques in a non-game context), app-based interventions can engage and influence people's beliefs, attitudes and behaviours. Gamification has not been applied to injury prevention. The aim of this study was to develop a gamified app-based intervention to prevent hot beverage scalds in young children.

Methods Randomised control trial. Participants recruited online via targeted social media advertisements. Inclusion criteria: mothers aged $18+$ with at least one child aged 5-12 months at time of recruitment, who own a Smartphone, and live in Queensland, Australia. Both groups complete a pre-test questionnaire to determine knowledge of hot beverage scald risks and burn first aid knowledge. Participants in the intervention group receive fortnightly messages (infographic or video) about hot drink scald risk factors and burn first aid treatment, and are incentivised with points and rewards/prizes. The control group receive three burn/ first aid infographics without incentives. After intervention period participants from both groups complete a post-test questionnaire.

Results The six-month intervention period will finish in July 2016. The anticipated sample size is 480 (240 intervention/240 control). Intervention effectiveness will be assessed using regression models adjusting for baseline values. Preliminary results will be presented.

Conclusions Given the success of gamified app-based interventions for chronic disease management, smoking cessation, and physical activity, it is hoped this novel approach to injury prevention will be equally successful. The low cost, scalability and broad reach make this approach an ideal channel for future injury prevention efforts.

\section{REACH OUT (I'LL BE THERE). RECEIVE-FOCUSED BEST PRACTICES FOR EFFECTIVE FIRE SAFETY CAMPAIGNS}

Maarit Pedak. University of Helsinki, Finland

10.1136/injuryprev-2016-042156.413

Background General public need to have basic knowledge about risks by potentially reducing the likelihood of future incidents. In order to prevent accidents and even loss of life there is fire safety campaigns The objective is that the messages will give information so that the people can protect themselves and their nearest and dearest. In an effort to understand better how to make risk messages more accessible and effective the campaigns are regularly evaluated by using performance indicator.

Methods The purpose of this study is to investigate how to design an efficient fire safety campaign. Resent Finnish fire safety campaigns will be analysed by using an empirically tested model of efficient risk communication. By using the IDEA-model as an analytical tool we can find efficient risk messages. Furthermore, we will identify the weaknesses of the messages related to the behavioural intentions they will create.

Results The hypothesis of this research is that instructional risk messages will aim higher degrees of self-efficacy and behavioural intention to take appropriate action. Instructions for self-protection and focusing on receiver-oriented strategies will increase comprehension, garner desired response, and produce appropriate self-protective action..

Conclusions Official risk communicators engaged with publics, and there is ongoing interest on how such communication could be most effective, with initial questions focused on message creation but expanding to query how audiences process and act on messages. Message receiver -oriented approach is needed instead of organisation-oriented when planning the campaigns. Hence, effective fire security campaigns must be evaluated based on accurate receiver interpretations and behavioural intentions.

\section{FIRE-RELATED MORTALITY IN SWEDEN-TEMPORAL TRENDS 1952-2013}

${ }^{1}$ Anders Jonsson, ${ }^{2}$ Marcus Runefors, ${ }^{3}$ Stefan Särdqvist, ${ }^{1}$ Finn Nilson. ${ }^{1}$ Karlstad University, Sweden; ${ }^{2}$ Lund University, Sweden; ${ }^{3}$ Swedish Civil Contingencies Agency, Sweden

\subsection{6/injuryprev-2016-042156.414}

Background The zero vision, declares that no one in Sweden should die or be seriously injured in fire-related incidents. In order to potentially reach this goal, historical trends are important to study to understand prevailing trends and emerging risk groups.

Methods This study examines temporal trends in deaths due to fire-related accidents in Sweden from1952 to 2013 based on statistics in the Cause of Death register held by the Swedish National Board of Health and Welfare. Fatalities coded with underlying cause of death associated with fire-related accidents are included and absolute numbers and age-adjusted mortality rates are calculated and statistically analysed for trends using Poisson regression.

Results We observed a significant reduction in both absolute numbers and in the age-adjusted mortality rate with a decline in absolute number of deaths of $34 \%$ over the period. However, the elderly population $(80+$ years $)$ showed a significant increase in absolute numbers. Regarding the age-adjusted mortality rate, a significant reduction of $63 \%$ was observed and children aged $0-4$ years showed the largest decrease (91\%). A reduction was seen both in terms of fatalities due to burns and carbon monoxide poisoning, although the reduction was more pronounced with regards to burns (69\% compared to $46 \%$ ).

Conclusions Although an overall decrease was observed in both absolute numbers and in the

age-adjusted mortality rate, with an ageing population, the absolute numbers of fire-related deaths for the elderly population will most likely increase in the future. Therefore, whilst previously a child-injury issue, fire-related deaths in Sweden is now 